Published in final edited form as:

J Orthop Trauma. 2016 March ; 30(3): 135-141. doi:10.1097/BOT.0000000000000475.

\title{
Character, Incidence, and Predictors of Knee Pain and Activity after Infrapatellar Intramedullary Nailing of an Isolated Tibia Fracture
}

\author{
William Obremskey, M.D., MPH MMHC ${ }^{1}$, Julie Agel ${ }^{2}$, Kristin Archer, D.P.T ${ }^{1}$, Philip To, M.D. ${ }^{1}$, \\ and Paul Tornetta, M.D. ${ }^{3}$ for the SPRINT Investigators \\ ${ }^{1}$ Vanderbilt Orthopaedic Institute, Nashville, Tennessee \\ ${ }^{2}$ University of Washington \\ ${ }^{3}$ Boston University
}

\section{Abstract}

Objective-To study the activity and incidence of knee pain after sustaining a isolated tibia fracture treated with an infrapatellar intramedullary nail at one year.

Design-Retrospective review of prospective cohort

Setting-Multicenter Academic and Community hospitals

Patients -437 patients with an isolated tibia fracture completed a 12 month assessment on pain and self-reported activity.

Intervention-Infrapatellar Intramedullary Nail

Outcomes-Demographic information co-morbid conditions, injury characteristics, and surgical technique were recorded. Knee pain was defined on a 1-7 scale with 1 being "no pain" and 7 being a "very great deal of pain." Knee pain $>4$ was considered clinically significant. Patients reported if they were "able", "able with difficulty" or "unable" to perform the following activities: kneel, run, climb stairs, and walk prolonged. Variables were tested in multilevel multivariable regression analyses.

Results-Knee Pain: $11 \%$ percent of patients reported a "good deal" to a "very great deal" of pain (> 4). 52\% of patients reported "no" or "very little" pain at 12 months. Activity at 12 months: $26 \%$ and $29 \%$ of patients were unable to kneel or run, respectively. $31 \%$ and $35 \%$ of patients respectively stated they were able with difficulty or unable to use stairs or walk.

Corresponding Author: William Obremskey MD, Vanderbilt Orthopaedic Institute, MCE, South Tower, Suite 4200, Nashville, TN, 37232-8828; william.obremskey@vanderbilt.edu.

Presented in part at the Annual Meeting of the Orthopaedic Trauma Association, Minneapolis, MN, October 2012.

Conflicts of Interest

There are no conflict of interests

Level of Evidence: Prognostic Level II. See Instructions for Authors for a complete description of levels of evidence. 
Conclusion-Clinically significant knee pain $(>4 / 7)$ was present in $11 \%$ of patients one year after a tibia fracture. $31 \%-71 \%$ of patients had difficulty performing or were unable to perform routine daily activities of kneeling, running, and stair climbing or walking prolonged distances.

\section{Keywords}

knee pain; tibia Fracture; functional outcome; intramedullary nail

\section{Introduction}

In the US, tibial shaft fractures are the most common long bone fracture and the incidence of knee pain is high ${ }^{1}$. A prospective randomized clinical trial was undertaken to compare the rate of re-operation for patients with tibial shaft fractures treated with either a reamed or unreamed nail (S.P.R.I.N.T) ${ }^{2}$. This trial enrolled 1,319 patients and concluded that for patients with closed fractures there was a benefit of a decreased rate of re-operation with a reamed intramedullary nail. The data did not demonstrate any difference in the rate of re-operation for patients with open fractures between treatment groups. Even though the tibia is a common fracture site, the magnitude of knee pain and their activity recovery are not well documented.

Knee pain is the most common complication following intramedullary nailing of the tibia, with an incidence reported to vary from $49-69 \%^{1-5}$. It has been theorized that the surgical approach to obtain the starting portal (i.e. lateral, medial, transtendonous) may affect knee pain. Early studies demonstrated a statistically difference between knee pain in medial parapatellar versus transtendonous insertion points ${ }^{5}$. However, Toivanen et al. prospectively studied 42 patients comparing medial parapatellar versus transtendonous nailing and found no significant difference in pain or function using a VAS, Lysholm, Tegner, and Iowa knee scoring systems ${ }^{4}$. A meta-analysis performed by Katsoulis et al. showed the incidence of knee pain to be $47 \%$, with no difference between approaches with respect to pain ${ }^{6}$. Little data is available to help determine the predictors of knee pain in patients after IMN for a tibia fracture ${ }^{6}$. Patients also frequently inquire what activities they will be able to perform once they have "recovered". No previous study has documented a patient's activity to allow physicians to adequately inform patients, so that both may have appropriate expectations.

The purpose of this study was to provide clinicians and patients with a clear understanding of incidence and magnitude of knee pain as well as activity capacity after sustaining an isolated tibia fracture treated with an infrapatellar intramedullary nail at one year, and the factors that affect knee pain and recovery.

\section{Patients and Methods}

The S.P.R.I.N.T. database (1227 patients) was reviewed to identify all patients who had sustained an isolated tibia fracture and had a one year follow-up on knee pain and/or activity $(\mathrm{n}=437)$ questionaires. All data was collected at a central coordinating center using methodology described in earlier publication. ${ }^{2}$ 
A similar tibia knee pain VAS scale used by Court-Brown ${ }^{1}$ was chosen for its specificity to the population under study and administered at 3,6 and 12 months. The tibia knee pain question was defined on a 1-7 scale with 1 being "no pain" and 7 being a "very great deal of pain." Knee pain > 4 was arbitrarily considered clinically significant. At the 12 month visit, patients answered a self-administered paper questionnaire that asked: "Currently are you able to kneel, climb stairs, walk for a prolonged period of time or run?", and checked a box that states "Unable", "Able with difficulty", or "Able".

In addition to standard demographic information (age, sex, race, and smoking status) injury characteristics (fracture location, presence of open wound, type of injury, AO/OTA classification $^{7}$, and surgical characteristics (incision length, approach (tendon split vs para tendon), type of entry portal into proximal tibia (superior - flat spot on proximal tibia on a lateral or inferior- adjacent to patellar tendon), type of nail, number of locking screws, and surgeon experience $(<5$ years vs $>5$ years of experience). We did not attain any pre-existing knee pain or activity function information on these patients.

\section{Statistical Analysis}

Descriptive statistics were used to explore the patient, injury and surgical characteristics included in the analyses. All continuous variables were examined for the assumptions required for parametric analyses.

Separate univariate and multivariate mixed-model regression analyses were performed to examine the relation between patient, injury, and surgical characteristics and pain scores as well as patient activity (ability to kneel, run, climb stairs, or walk prolonged distances). All models included a random effect to account for the clustering of patients by clinical site. Variables that were significant at $\mathrm{p}<.05$ in univariate analysis or a priori considered relevant to the outcomes from a clinical or theoretical perspective were entered into each multivariate model for analysis. These a priori variables included approach (tendon split vs paratendon), type of entry portal (superior/inferior), fracture location (proximal, middle, distal), type of fracture pattern (42A, B or C) and type of open fracture (Type 1,2,3). STATA 12 software (StataCorp. 2011. Stata Statistical Software: Release 12. College Station, TX: StataCorp LP) was used to analyze the data. The level of significance was set at $\mathrm{p}<.05$.

All sites that collected data during this project had IRB approval. The clinical trials identifier is NCT00038129. All funding for this project came from NIH R01-AR48529 and CIHR MCT-38140.

\section{Results}

Twenty-nine sites across the United States, Canada, and the Netherlands enrolled 1,226 patients with tibial shaft fractures amenable to treatment by intramedullary nail over a 62 month period and had complete demographic, injury, and treatment data. One-year follow up was available for 910 patients of these patients 437 patients had an isolated tibia fracture. Injury and surgical characteristics of the study population are presented in Table 1. 
The percent of patients with a "good" to a "very great" deal of knee pain (>4) was $11 \%$ at 12 months. 51\% of patients reported "no" or "very little" knee pain at 12 months. Amount of pain patients perceived consistently decreased over time from 3-12 months. (Table 2)

At 12 months, $26 \%$ and $29 \%$ of patients were unable to kneel and run, respectively. The percent of patients who said they were 'able with difficulty' or 'unable' to climb stairs was $31 \%$ and walk prolonged was $35 \%$. (See Table 3 )

Multivariate predictors of increased knee pain were being a current smoker, having a comminuted fracture pattern $(42 \mathrm{C})$ and having a surgeon with less than 5 years of experience $(\mathrm{p}<0.05)$. All other variables were not significant. (Table 4)

Mulitvariate predictors of a patient being unable to perform an activity: kneel; walk, use stairs, and run were also assessed in a regression model. Women had more difficulty kneeling $(\mathrm{p}<0.05)$. Stair climbing was more difficult in patients who were older, smokers, and if patient had open or proximal fractures $(\mathrm{p}<0.05)$. Walking was also more difficult in patients who were older, smokers or had an open fracture $(\mathrm{p}<0.05)$. All other variables for each activity were not significant (Table 5).

\section{Discussion}

This is the largest study to our knowledge examining tibial intramedullary nailing (IMN). Our study showed that at 1 year $11 \%$ of patients complained of significant knee pain and the predictors of knee pain were smoking, comminuted fractures, and surgeons with less than 5 years of experience.

Our incidence of significant knee pain (11\%) is lower than previously published data. Multiple studies with small cohorts have reported on knee pain associated with tibia fractures with incidence and severity ranging greatly. 1,3-6, 8, 15-18-25 Court-Brown et al. followed one of the largest series of 169 patients and found a 56\% incidence of knee pain ${ }^{1}$. However, the study included mild pain in the total percent of patients with pain. 56\% (95/169) patients stated they had a least some pain at insertion site; 6\% (10/169) patients had occasional global pain with activity and $42 \%$ (64/169) patients had no pain at all. Our study identified patients with moderate or severe knee pain. In Court-Brown's study $18 \%$ of patients (30/169) had "moderate (4-6/10) or severe (>6/10)" pain. The large discrepancy of knee pain incidence between studies could be due in part to a lack of a standard definition and severity of knee pain. Court-Brown utilized a 10 point VAS scale and considered pain $>6 / 10$ as significant pain. The SPRINT study steering committee selected a knee pain scored from 1-7 where 1 is no pain and 7 is a "very great deal of pain" with pain $>4 / 7$ arbitrarily was considered significant pain.

A more recent article by Song et al. on anterior knee pain using an infrapatellar medial approach similar to our study found moderate to severe knee pain in $28 \%$ of all patients using a 0-3 pain scale with pain reported as Moderate or severe as a score of 2 or 3 respectively.19 Knee pain in Knee pain in the Song article was significantly related to superior nail prominence and nail-apex distance. We have no explanation of why this study had a higher incidence of similarly assess knee pain in the Asian population. Pain is tightly 
related to patient expectations and cultural norms. These may be different in the population study in the Song article. ${ }^{20,21}$

Intramedullary nailing of proximal tibia fractures has been shown to result in frequent malalignment. Semi-extended nailing of these fractures has been assessed and found to have improved alignment and no differences in postoperative knee pain. ${ }^{22} \mathrm{~A}$ case series of proximal and distal tibia fractures treated with a semi-extended technique were compared to patients with a diaphyseal fracture that underwent standard intramedullary IMN placement with a medial parapatellar incision. No patient had a malalignment or a loss of reduction. Any knee pain was present in $17 \%$ of patients with a semi-extended technique and in $20 \%$ of patients with a standard medial parapatellar. Moderate or severe knee pain was seen in $6 \%$ of patients with a semi-extended position in $8 \%$ in patients with a standard portal. No statistically significant differences were seen in knee pain with either approach.

Semi-extended nailing is also been study utilizing a suprapatellar approach to the starting point. Sanders et al. ${ }^{23} 36$ patients were available at 1 year follow-up $97.2 \%$ (35/36) reported no pain with a 10 point VAS score of 0 . One patient reported a VAS score of 2 at the suprapatellar entry site (22) no cartilage damage was noted in 13 of 15 patients undergoing arthroscopic evaluation of the knee joint. It is unclear if suprapatellar intramedullary nailing has a lower incidence of knee pain after stabilization of a tibia fracture with an intramedullary rod versus an infrapatellar approach. A retrospective analysis of consecutive patients treated with either a suprapatellar approach or an infrapatellar approach was completed by Jones et al. ${ }^{24}$. No differences were seen in knee pain score using the Kujala score as measure of anterior knee pain. Also no differences were seen in the physical or mental components of the SF-12 between these groups. Improved fracture reduction was seen in the sagittal and coronal plane in the suprapatellar versus the infrapatellar group. Improved insertion point was also thought to be more accurate in the suprapatellar group.

The cause of the knee pain is unknown at this time. Proposed causes of knee pain are nail prominence ${ }^{8}$ damage to Hoffa fat pad $^{8}$, infrapatella nerve injury, ${ }^{9}$ quadriceps weakness ${ }^{10}$ union $^{11}$, and intraarticular injury ${ }^{12}$. Presence of an incision over the anterior knee may be a determining factor to anterior knee pain after intramedullary fixation of a tibial fracture. The Sanders article (23) and a report by Ramos (25) found essentially no anterior knee pain. The Sanders article utilized a suprapatellar portal and the Ramos article compared Ilizarov external fixators with standard intramedullary nailing in diaphyseal tibia fractures in a respective control trial. At 1 year patients in the Ilizarov group had lower VAS pain scores then patient's treated with a intramedullary nail $(\mathrm{p}=0.03) . \mathrm{K}$

Anterior cortical bone loss has also been proposed as an etiology knee pain due to tibial nail insertion due to altered biomechanics of the proximal tibia. (26) anterior cortical defects are present with her the IM nail was placed in a infrapatellar or a suprapatellar technique. (27) Our study identified smoking as a predictor of knee pain. Ryan et al. showed an inverse relationship between smoking and union ${ }^{11}$. In their study, they showed that the first 20 weeks after surgery the more knee pain was associated with a lower the radiographic union score. After 20 weeks, union score and knee pain did not correlate. Smoking has long been associated with poor wound and bone healing. A recent animal study showed that 
transdermal nicotine had higher rate of nonunion and decreased mechanical strength ${ }^{13}$. We hypothesize that smoking slows fracture union and could be a reason why "smoking" is a significant predictor of knee pain. Suprapatellar IMN technique was also not used in this study as the study was completed prior to introduction and adoption of this technique. We did not record union or time to union in this study. The SPRINT recorded mechanical failure of locking bolts and reoperation for nonunion as treatment failures. By protocol all IMNs were locked with 2 proximal locking bolts so no correlation was found with number of locking bolts.

We did not find that knee pain at one year after injury was predicted by: open/closed, location of fracture; technical aspects: portal, approach, length of incision, type of IMN or number of proximal locking bolts.

Having a surgeon with less than 5 years of experience was a predictor of knee pain. We are unsure of the etiology of this association. Surgeons with less experience could be errant in locating the starting point. If the starting point is not within the "safe zone" as described by Tornetta, then intrarticular structures could be injured ${ }^{12}$. Studies on arthroscopy have demonstrated surgical experience led to improved psychomotor skills. ${ }^{14}$ This may be true in tibia fracture surgery as well. Inexperience could lead to multiple starting points, which could cause intra-articular damage and pain.

Our study showed that women had more pain with kneeling than men. Again we are unsure of the etiology of this association. Cartwright-Terry et al demonstrated $81 \%$ of patients had pain with kneeling ${ }^{15}$. Song et al found that $100 \%$ patients with moderate to severe pain had pain with kneeling. ${ }^{16}$ Unlike this study, Song et al found that age and sex did not correlate with pain. Court-Brown et al ${ }^{1}$ and Keating et al ${ }^{17}$ both found that younger patients and females also had more knee pain. They believed that younger patients were more active which contributed to more pain. Our study did not find age to be a predictor of knee pain.

Devitt et al performed a biomechanical study showing that there are increased patellofemoral forces during reaming. ${ }^{18}$ This increased force could lead to chondral injury and be a possible cause for knee pain. Our study confirmed what previous studies have shown on surgical approaches. We found no correlation between transtendinous or paratendinous approaches and knee pain. Although there is some debate, the best evidence was reported by Toivanen et al. They performed a prospective randomized trial of surgical approaches and found no differences between the two approaches at 3 and 8 years of follow up $^{4,19}$. No patient in this study had a suprapatellar IMN technique utilized.

Another theory of knee pain is that it may be related to patella fat pad injury. A basic science study demonstrated that fat pad edema can increase patella-femoral strain. ${ }^{228}$ Fat pad hypertrophy and impingement damage to it during IMN placement may also contribute to knee pain and removal has decreased anterior knee pain. ${ }^{29,30}$

A patient's capacity to resume daily life and athletic activity is also a common question for surgeons. This report found at 12 months, $26 \%$ and $29 \%$ of patients were unable to kneel and run, respectively. The percent of patients who said they were 'able with difficulty' or 'unable' to climb stairs was $31 \%$ and walk prolonged was $35 \%$. These data indicate that 
patients commonly have significant restrictions to daily activity. Larsen et al. reviewed 294 patients nearly 8 years from injury. 39\% indicated dysfunction daily living, 50\% indicated limitations in quality of life and 6\% indicated limitations during sports activity (31) Our data is consistent with the Larsen data that indicate that a tibia fracture has a significant longterm impact on a patients' ability to perform day-to-day activities and on quality of life

Strengths of the study include the large cohort size and its generalizability. This cohort also had multiple centers and surgeons involved.

Our study has a few weaknesses. This is a post hoc evaluation of prospectively gathered data. The incidence of knee pain was not a planned primary or secondary outcome of the SPRINT study ${ }^{2}$. We did not have pre-injury assessment of knee pain or activity so we are unable to assess what if any change has occurred due to the injury or surgery. We also did not use identical measures of knee pain as other investigators and the pain and activity measure were not validated. The analysis of etiology and predictors of knee pain in tibia fractures was not an a priori hypothesis of the SPRINT study. We did not use a validated outcome measure for pain assessment, but a similar methodology has been used in prior studies of knee pain after tibia fracture stabilization with an IMN. Court-Brown and others in smaller series used a VAS score to assess knee pain. We did not assess quad strength between sides of compared to norms. Quad strength certainly can be associated with knee pain. We also could have selection bias as patients that returned for one year follow up may be more likely to have pain than those who did not follow up.

We did find age as a risk factor for decreased capacity to walk and use stairs. We did not compare patients' ability to perform activity prior to injury and age may be a predictor of decreased activity in patients' without injury. We excluded multiple trauma patients to assure knee pain or activity was not due other associated injuries. Also although the effect of age on activity capability as statistically significant, it is likely clinically irrelevant as the odds ratio was 1.01. This is a small difference but significant due a slight difference in age and a large number of patients. Our follow up is limited to 1 year. However, most surgeons follow up patients with a tibia fracture treated with a tibial nail only up to year.

\section{Conclusion}

Clinically significant knee pain (>4/7) was present in $11 \%$ of patients one year after a tibia fracture that is stabilized with an IMN. Overall patients demonstrate significant impact on their life and function due to pain and diminished activity levels. $31 \%$ to $71 \%$ of patients had difficulty performing or were unable to perform routine daily activities of kneeling, running, stair climbing or walking prolonged distances at one year after injury. Patient smoking was the factor that most consistently predicted knee pain.

These results are particularly enlightening as this is by far the largest cohort of patients with a tibia fracture to be studied for knee pain and activity. These results can be used to provide reasonable expectations to physicians and patients on knee pain and activity after an infrapatellar IMN for an isolated unstable tibia fracture. The knee pain data of this study 
may or may not apply to patients who have a tibial IMN placed with a suprapatellar technique, but the significant activity restrictions are likely to be similar.

\section{Acknowledgments}

Source of Funding:

Research grants were received from the following: Canadian Institutes of Health Research \#MCT-38140 (PI: Gordon Guyatt); National Institutes of Health (NIAMS-072 and R01-AR48529) (PI: Marc Swiontkowski); Orthopaedic Research and Education Foundation of the American Academy of Orthopaedic Surgeons (PI: Paul Tornetta, III); Orthopaedic Trauma Association (PI: Mohit Bhandari); Hamilton Health Sciences Research Grant (PI: Mohit Bhandari); and Zimmer Corp. (PI: Mohit Bhandari). Mohit Bhandari was also funded, in part, by a Canada Research Chair in Musculoskeletal Trauma (McMaster University, Hamilton, ON, Canada). The funding sources had no role in influencing the project or manuscript. Diane Heels-Ansdell, MSc (Department of Clinical Epidemiology and Biostatistics, McMaster University, Hamilton, ON, Canada), analyzed the data under the supervision of Stephen Walter (Senior Biostatistician).

\section{The following persons participated in the SPRINT Study}

Study Trial Co-Principal Investigators: Mohit Bhandari; Gordon Guyatt; Steering Committee: Chair: Gordon Guyatt; Mohit Bhandari; David W. Sanders; Emil H. Schemitsch; Marc Swiontkowski; Paul Tornetta III; Stephen Walter; Central Adjudication Committee: Chair: Gordon Guyatt; Mohit Bhandari; David W. Sanders; Emil H. Schemitsch; Marc Swiontkowski.; Paul Tornetta III; Stephen Walter; SPRINT Methods Center Staff: McMaster University, Hamilton, Ontario: Sheila Sprague; Diane HeelsAnsdell; Lisa Buckingham; Pamela Leece; Helena Viveiros; Tashay Mignott; Natalie Ansell; Natalie Sidorkewicz; University of Minnesota, Minneapolis, Minnesota: Julie Agel; Data Safety and Monitoring Board (DSMB): Chair: Claire Bombardier; Jesse A. Berlin; Michael Bosse; Bruce Browner; Brenda Gillespie; Alan Jones; Peter O’Brien; Site Audit Committee: Julie Agel; Sheila Sprague; Rudolf Poolman; Mohit Bhandari.

Investigators: London Health Sciences Center / University of Western Ontario, London, Ontario: David W. Sanders; Mark D. Macleod; Timothy Carey; Kellie Leitch; Stuart Bailey; Kevin Gurr; Ken Konito; Charlene Bartha; Isolina Low; Leila V. MacBean; Mala Ramu; Susan Reiber; Ruth Strapp; Christina Tieszer; Sunnybrook Health Sciences Center / University of Toronto, Toronto, Ontario: Hans J. Kreder; David J. G. Stephen; Terry S. Axelrod; Albert J.M. Yee; Robin R. Richards; Joel Finkelstein; Wade Gofton; John Murnaghan; Joseph Schatztker; Michael Ford; Beverly Bulmer; Lisa Conlan; Hospital du Sacre Coeur de Montreal, Montreal, Quebec: G. Yves Laflamme; Gregory Berry; Pierre Beaumont; Pierre Ranger; Georges-Henri Laflamme; Sylvain Gagnon; Michel Malo; Julio Fernandes; Marie-France Poirier; St. Michael's Hospital / University of Toronto, Toronto, Ontario: Emil H. Schemitsch; Michael D. McKee; James P. Waddell; Earl R. Bogoch; Timothy R. Daniels; Robert R. McBroom; Milena R. Vicente; Wendy Storey; Lisa M. Wild; Royal Columbian Hospital / University of British Columbia, New Westminster/Vancouver, British Columbia: Robert McCormack; Bertrand Perey; Thomas J. Goetz; Graham Pate; Murray J. Penner; Kostas Panagiotopoulos; Shafique Pirani; Ian G. Dommisse; Richard L. Loomer; Trevor Stone; Karyn Moon; Mauri Zomar; Wake Forest Medical Center / Wake Forest University Health Sciences, Winston-Salem, North Carolina: Lawrence X. Webb; Robert D. Teasdall; John Peter Birkedal; David Franklin 
Martin; David S. Ruch; Douglas J. Kilgus; David C. Pollock; Mitchel Brion Harris; Ethan Ron Wiesler; William G. Ward; Jeffrey Scott Shilt; Andrew L. Koman; Gary G. Poehling; Brenda Kulp; Boston Medical Center / Boston University School of Medicine, Boston, Massachusetts: Paul Tornetta III; William R. Creevy; Andrew B. Stein; Christopher T. Bono; Thomas A. Einhorn; T. Desmond Brown; Donna Pacicca; John B. Sledge III; Timothy E. Foster; Ilva Voloshin; Jill Bolton; Hope Carlisle; Lisa Shaughnessy; Wake Medical Center, Raleigh, North Carolina: William T. Obremskey; C. Michael LeCroy; Eric G. Meinberg; Terry M. Messer; William L. Craig III; Douglas R. Dirschl; Robert Caudle; Tim Harris; Kurt Elhert; William Hage; Robert Jones; Luis Piedrahita; Paul O. Schricker; Robin Driver; Jean Godwin; Vanderbilt University Medical Center, Nashville, Tennessee: William T. Obremskey; Philip James Kregor; Gregory Tennent; Lisa M. Truchan; Marcus Sciadini; Franklin D. Shuler; Robin E. Driver; Mary Alice Nading; Jacky Neiderstadt; Alexander R. Vap; MetroHealth Medical Center, Cleveland, Ohio: Heather A. Vallier; Brendan M. Patterson; John H. Wilber; Roger G. Wilber; John K. Sontich; Timothy Alan Moore; Drew Brady; Daniel R. Cooperman; John A. Davis; Beth Ann Cureton; Hamilton Health Sciences, Hamilton, Ontario: Scott Mandel; R. Douglas Orr; John T.S. Sadler; Tousief Hussain; Krishan Rajaratnam; Bradley Petrisor; Mohit Bhandari; Brian Drew; Drew A. Bednar; Desmond C.H. Kwok; Shirley Pettit; Jill Hancock; Natalie Sidorkewicz; Regions Hospital, St. Paul, Minnesota: Peter A. Cole; Joel J. Smith; Gregory A. Brown; Thomas A. Lange; John G. Stark; Bruce A. Levy; Marc F. Swiontkowski; Mary J. Garaghty; Joshua G. Salzman; Carol A. Schutte; Linda Tastad; Sandy Vang; University of Louisville School of Medicine, Louisville, Kentucky: David Seligson; Craig S. Roberts; Arthur L. Malkani; Laura Sanders; Carmen Dyer; Jessica Heinsen; Langan Smith; Sudhakar Madanagopal; Linda Frantz-Bush; Memorial Hermann Hospital, Houston, Texas: Kevin J. Coupe; Jeffrey J. Tucker; Allen R. Criswell; Rosemary Buckle; Alan Jeffrey Rechter; Dhiren Shaskikant Sheth; Brad Urquart; Thea Trotscher; Erie County Medical Center / University of Buffalo, Buffalo, New York: Mark J. Anders; Joseph M. Kowalski; Marc S. Fineberg; Lawrence B. Bone; Matthew J. Phillips; Bernard Rohrbacher; Philip Stegemann; William M. Mihalko; Cathy Buyea; University of Florida - Jacksonville, Jacksonville, Florida: Stephen J. Augustine; William Thomas Jackson; Gregory Solis; Sunday U. Ero; Daniel N. Segina; Hudson B. Berrey; Samuel G. Agnew; Michael Fitzpatrick; Lakina C. Campbell; Lynn Derting; June McAdams; Academic Medical Center, Academic Medical Center, Amsterdam, The Netherlands: J. Carel Goslings; Kees Jan Ponsen; Jan Luitse; Peter Kloen; Pieter Joosse; Jasper Winkelhagen; Raphaël Duivenvoorden; University of Oklahoma Health Science Center, Oklahoma City, Oklahoma: David C. Teague; Joseph Davey; J. Andy Sullivan; William J. J. Ertl; Timothy A. Puckett; Charles B. Pasque; John F. Tompkins II; Curtis R. Gruel; Paul Kammerlocher; Thomas P. Lehman; William R. Puffinbarger; Kathy L. Carl; University of Alberta / University of Alberta Hospital / Royal Alexandra Hospital, Edmonton, Alberta: Donald W. Weber; Nadr M. Jomha; Gordon R. Goplen; Edward Masson; Lauren A. Beaupre; Karen E. Greaves; Lori N. Schaump; Greenville Hospital System, Greenville, South Carolina: Kyle J. Jeray; David R. Goetz; David E. Westberry; J. Scott Broderick; Bryan S. Moon; Stephanie L. Tanner; Foothills General Hospital, Calgary, Alberta: James N. Powell; Richard E. Buckley; Leslie Elves; Saint John Regional Hospital, Saint John, New Brunswick: Stephen Connolly; Edward P. Abraham; Trudy Steele; Oregon Health \& Sciences University, 
Portland, Oregon: Thomas Ellis; Alex Herzberg; George A. Brown; Dennis E. Crawford; Robert Hart; James Hayden; Robert M. Orfaly; Theodore Vigland; Maharani Vivekaraj; Gina L. Bundy; University of California, San Francisco, San Francisco General Hospital, San Francisco, California: Theodore Miclau III; Amir Matityahu; R. Richard Coughlin; Utku Kandemir; R. Trigg McClellan; Cindy Hsin-Hua Lin; Detroit Receiving Hospital, Detroit, Michigan: David Karges; Kathryn Cramer; J. Tracy Watson; Berton Moed; Barbara Scott; Deaconess Hospital Regional Trauma Center and Orthopaedic Associates, Evansville, Indiana: Dennis J. Beck; Carolyn Orth; Thunder Bay Regional Health Science Center, Thunder Bay, Ontario: David Puskas; Russell Clark; Jennifer Jones; Jamaica Hospital, Jamaica, New York: Kenneth A. Egol; Nader Paksima; Monet France; Ottawa Hospital - Civic Campus, Ottawa, Ontario: Eugene K. Wai; Garth Johnson; Ross Wilkinson; Adam T. Gruszczynski; Liisa Vexler.

\section{References}

1. Court-Brown CM, Gustilo T, Shaw AD. Knee pain after intramedullary tibial nailing: its incidence, etiology, and outcome. Journal of Orthopaedic Trauma. 1997 Feb-Mar;11(2):103-5. [PubMed: 9057144]

2. Bhandari M, Guyatt G, Tornetta P 3rd, Schemitsch E, Swiontkowski M, Sanders D, Walter SD. SPRINT Investigators. Study to prospectively evaluate reamed intramedullary nails in patients with tibial fractures (S.P.R.I.N.T.): Randomized Trial of Reamed and Unreamed Intramedullary Nailing of Tibial Shaft Fractures. JBJS. Dec.2008 90:2567-2578.

3. Bhattacharyya, et al. Knee pain after Tibial Nailing: the Role of Nail Prominence. Clinical Orthopaedics and Related Research. 2006; 449:303-307. [PubMed: 16702914]

4. Toivanen. Anterior Knee Pain After Intramedullary Nailing of Fractures of the Tibial Shaft: A Prospective, Randomized Study Comparing Two Different Nail-Insertion Techniques. J Bone Joint Surg AM. 2002; 84:580-585. [PubMed: 11940618]

5. Orfaly R, Keating J, O’Brien PJ. Knee Pain After Tibial Nailing: Does the Entry Point Matter? J Bone Joint Surg (Br). 1995; 77-B:976-977. [PubMed: 7593119]

6. Katsoulis E, Court-Brown C, Giannoudis PV. Incidence and Aetiology of Anterior Knee Pain after Intramedullary Nailing of the Femur and Tibia. J Bone Join Surg Br. 2006; 88-B:576-79.

7. Marsh JL, Slongo TF, Agel J, et al. Fracture and dislocation classification compendiumV2007: Orthopaedic Trauma Association classification, database and outcomes committee. J Orthop Trauma. 2007; 21(Suppl) S1YS133.

8. Bhattacharyyra T, et al. Knee Pain after Tibial Nailing the Role of Nail Prominence. Clin Orthop Related Research. Aug.2006 449:303-307.1 Weninger P, et al. Anatomical Assessment of the Hoffa Fat Pad During Insertion of a Tibial Intramedullary Nail—Comparison of Three Surgical Approaches. J Trauma. Apr.2009 66:1140-1145. [PubMed: 19359927]

9. Lelivld MS, Verhofstad MHJ. Injury to the infrapatellar branch of the saphenous nerve, a possible cause for anterior knee pain after tibial nailing? Injury. 2012; 43:779-783. [PubMed: 21962297]

10. Väistö O, et al. Anterior Knee Pain and Thigh Muscle Strength After Intramedullary Nailing of Tibial Shaft Fractures. J Orthop Trama. Jan.2004 18:18-24.

11. Ryan SP, Tornetta P 3rd, Dielwart C, Kaye-Krall E. Knee Pain correlates with Union after Tibial Nailing. J Orthop Trauma. Dec; 2011 25(12):731-735. [PubMed: 21886000]

12. Tornetta P, Riina J, Geller J, et al. Intra-articular anatomic risks of tibial nailing. J Orthop Trauma. 1999; 13:247-251. [PubMed: 10342349]

13. Donigan JA, Fredericks DC, Nepola JV, Smucker JD. The effect of transdermal nicotine on fracture healing in a rabbit model. Journal of Orthopaedic Trauma. 2012 Dec; 26(12):724-7. [PubMed: 22955337]

14. Howells NR, et al. Transferring simulated arthroscopic skills to the operating theatre: a randomised blinded study. J Bone Joint Surg Br. Apr; 2008 90(4):494-499. [PubMed: 18378926] 
15. Cartwright-Terry M, Snow M, Nalwad H. The Severity and Prediction of Anterior Knee Pain Post Tibial Nail Insertion. J Orthop Trauma. Jul; 2007 21(6):381-385. [PubMed: 17620996]

16. Song SY, Chang HG, Byun JC, Kim TY. Anterior Knee Pain After Tibial Intramedullary Nailing Using a Medial Paratendinous Approach. J Orthop Trauma. Mar; 2012 26(3):172-177. [PubMed: 22068208]

17. Keating JF, Orfaly R, O’Brien PJ. Knee pain after tibial nailing. J Orthop Trauma. 1997; 11:10-13. [PubMed: 8990026]

18. Devitt AT, Coughlan KA, Ward T, et al. Patello-femoral contact forces and pressures during intramedullary tibial nailing. Int Orthop. 1998; 22:92-96. [PubMed: 9651773]

19. Vaisto O, Toivanen, Kannus P, et al. Anterior Knee Pain After Intramedullary Nailing of Fractures of the Tibial Shaft: An eight year follow up of a Prospective, Randomized Study Comparing Two Different Nail-Insertion Techniques. J Trauma. 2008; 64:1511-1516. [PubMed: 18545115]

20. Song, Si Young; Chang, Ho Geun; Byun, Jae Chul. More. Anterior Knee Pain After Tibial Intramedullary Nailing Using a Medial Paratendinous Approach. Journal of Orthopaedic Trauma. Mar; 2012 26(3):172-177. [PubMed: 22068208]

21. Chen CY, Lin KC. Anterior knee pain. J Orthop Trauma (United States). Jan.2013 27(1):pe24.

22. Ryan SP, Steen B, Tornetta P. Semi-extended nailing of metaphyseal tibia fractures: alignment and incidence of postoperative knee pain. J Orthop Trauma (United States). May; 2014 28(5):p263-9.

23. Sanders RW, Di Pasquale TG, Jordan CJ, et al. Semiextended intramedullary nailing of the tibia using a suprapatellar approach: radiographic results and clinical outcomes at a minimum of 12 months follow-up. J Orthop Trauma (United States). May; 2014 28(5):p245-55.

24. Jones, Mark; Parry, Michael; Whitehouse, Michael. More. Radiologic Outcome and PatientReported Function After Intramedullary Nailing: A Comparison of the Retropatellar and Infrapatellar Approach. Journal of Orthopaedic Trauma. May; 2014 28(5):256-262. [PubMed: 24464093]

25. Ramos T, Eriksson BI, Karlsson J, et al. Ilizarov external fixation or locked intramedullary nailing in diaphyseal tibial fractures: a randomized, prospective study of 58 consecutive patients. Arch Orthop Trauma Surg (Germany). Jun; 2014 134(6):p793-802.

26. Mir HR, Marinescu RC, Janda H, Russell TA. Biomechanical Effects of the Nail Entry Zone and Anterior Cortical Bone Loss on the Proximal Tibia. Journal of Orthopaedic Trauma. Jan; 2013 27(1):34-41. [PubMed: 22588531]

27. Bible, Jesse E.; Choxi, Ankeet A.; Dhulipala, Sravan; Evans, Jason M.; Mir, Hassan. Quantification of Anterior Cortical Bone Removal and Intermeniscal Ligament Damage at the Tibial Nail Entry Zone Using Parapatellar and Retropatellar Approaches. Journal of Orthopaedic Trauma. Aug; 2013 27(8):437-441. [PubMed: 23287753]

28. Bohnsack M, Klages P, Hurschler C, Halcour A, Wilharm A, Ostermeier S, Ruhmann O, Wirth CJ. Influence of an infrapatellar fat pad edema on patellofemoral biomechanics and knee kinematics: a possible relation to the anterior knee pain syndrome. Archives of Orthopaedic \& Trauma Surgery. 2009 Aug; 129(8):1025-30. [PubMed: 17053945]

29. von Engelhardt LV, Tokmakidis E, Lahner M, David A, Haage P, Bouillon B, Lichtinger TK. Hoffa's fat pad impingement treated arthroscopically: related findings on preoperative MRI in a case series of 62 patients. Archives of Orthopaedic \& Trauma Surgery. 2010 Aug; 130(8):104151. [PubMed: 20556618]

30. Kumar D, Alvand A, Beacon JP. Impingement of infrapatellar fat pad (Hoffa's disease): results of high-portal arthroscopic resection. Arthroscopy. 2007 Nov; 23(11):1180-1186.e1. [PubMed: 17986405]

31. Larsen P, Lund H, Laessoe U, Graven-Nielsen T, Rasmussen S. Restrictions in Quality of Life After Intramedullary Nailing of Tibial Shaft Fracture: A Retrospective Follow-up Study of 223 Cases. Journal of Orthopaedic Trauma. Sep; 2014 28(9):507-512. [PubMed: 24164788] 
Table 1

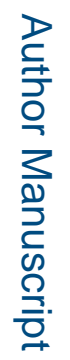

Patient, injury and surgical characteristics of study population $(\mathrm{N}=437)$

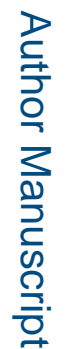

\begin{tabular}{|l|l|}
\hline & $\mathbf{N}(\%)$ \\
\hline Age in years, mean (SD) & $41.9(15.6)$ \\
\hline Sex & \\
Male & $311(71 \%)$ \\
Female & $126(29 \%)$ \\
\hline Race & \\
Non White & $68(16 \%)$ \\
White & $369(84 \%)$ \\
\hline Smoking Status & \\
Never/Former & $314(72 \%)$ \\
Current & $123(28 \%)$ \\
\hline
\end{tabular}

Fracture Location

Proximal

$35(8 \%)$

Diaphyseal

$85(19 \%)$

Distal

$317(73 \%)$

\begin{tabular}{l|l}
\hline $\begin{array}{l}\text { Wound Type } \\
\text { Closed }\end{array}$ & $331(76 \%)$ \\
Open & $106(24 \%)$ \\
\hline
\end{tabular}

Fasciotomy at initial surgery

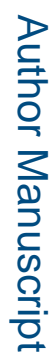

No

$428(98 \%)$

Yes

$9(2 \%)$

Injury Type

Low Energy

$235(54 \%)$

High Energy

$202(46 \%)$

AO Class

A

$267(61 \%)$

B

$125(29 \%)$

C

$45(10 \%)$

Fracture gap

No gap

$398(91 \%)$

Gap $<1 \mathrm{~cm}$

$25(6 \%)$

Gap $>=1 \mathrm{~cm}$

$14(3 \%)$

Tendon Approach

Medial Paratendinous

$337(77 \%)$

Tendon Split

$100(23 \%)$

J Orthop Trauma. Author manuscript; available in PMC 2017 March 01. 


\begin{tabular}{|c|c|c|}
\hline \multirow{7}{*}{ 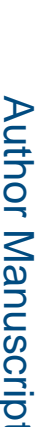 } & & $\mathbf{N}(\%)$ \\
\hline & \multirow{3}{*}{$\begin{array}{c}\text { Entry Portal } \\
\text { Superior } \\
\text { Inferior }\end{array}$} & \\
\hline & & $329(75 \%)$ \\
\hline & & $108(25 \%)$ \\
\hline & \multirow{3}{*}{$\begin{array}{l}\text { Nail Type } \\
\text { Stainless Steel } \\
\text { Titanium }\end{array}$} & \\
\hline & & $154(35 \%)$ \\
\hline & & $283(65 \%)$ \\
\hline & \multirow{3}{*}{$\begin{array}{l}\text { Locking screws } \\
\text { None/1+ } \\
2+\end{array}$} & \\
\hline & & $207(47 \%)$ \\
\hline & & $230(53 \%)$ \\
\hline & \multirow{3}{*}{$\begin{array}{l}\text { Type of Surgeon } \\
>5 \text { years Experience } \\
<5 \text { years Experience }\end{array}$} & \\
\hline$D$ & & $158(36 \%)$ \\
\hline$\stackrel{c}{\rightleftarrows}$ & & $279(64 \%)$ \\
\hline 은 & \multirow{3}{*}{$\begin{array}{l}\text { Full weight bearing } \\
\text { No } \\
\text { Yes }\end{array}$} & \\
\hline $\overrightarrow{\mathrm{D}}$ & & $390(89 \%)$ \\
\hline 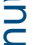 & & $47(11 \%)$ \\
\hline
\end{tabular}

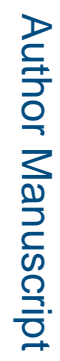

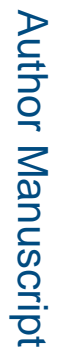

J Orthop Trauma. Author manuscript; available in PMC 2017 March 01. 
Table 2

Distribution of Knee pain at 3, 6 and 12 month follow-up.

\begin{tabular}{|l|c|c|c|}
\hline & 3 Month $(\mathbf{N}=393)$ & $\mathbf{6}$ Month $(\mathbf{N}=\mathbf{3 6 1})$ & 12 Month $(\mathbf{N}=\mathbf{4 2 8})$ \\
\hline Knee Pain Score & $\mathbf{N}(\%)$ & $\mathbf{N}(\%)$ & $\mathbf{N}(\%)$ \\
\hline 1 & $65(17 \%)$ & $86(24 \%)$ & $101(24 \%)$ \\
\hline 2 & $112(29 \%)$ & $113(31 \%)$ & $118(28 \%)$ \\
\hline 3 & $104(26 \%)$ & $81(22 \%)$ & $103(24 \%)$ \\
\hline 4 & $71(18 \%)$ & $46(13 \%)$ & $57(13 \%)$ \\
\hline 5 & $25(6 \%)$ & $17(5 \%)$ & $36(8 \%)$ \\
\hline 6 & $9(2 \%)$ & $10(3 \%)$ & $7(2 \%)$ \\
\hline 7 & $7(2 \%)$ & $8(2 \%)$ & $6(1 \%)$ \\
\hline Average Score (SD): & $2.9(1.4)$ & $2.8(1.4)$ & $2.7(1.4)$ \\
\hline
\end{tabular}

Note. $1=$ no pain; $2=$ very little pain; $3=$ some pain; $4=$ a moderate amount of pain; $5=$ a good deal of pain; $6=$ a great deal of pain; $7=$ a very great deal of pain 
Table 3

Activity level 12 months after IMN of Tibia fracture $(\mathrm{N}=437)$

\begin{tabular}{|l|l|l|l|}
\hline Activity & Unable & Able w/Difficulty & Able \\
\hline Kneel & $26 \%$ & $45 \%$ & $29 \%$ \\
\hline Walk & $7 \%$ & $28 \%$ & $65 \%$ \\
\hline Stairs & $3 \%$ & $28 \%$ & $69 \%$ \\
\hline Run & $29 \%$ & $37 \%$ & $35 \%$ \\
\hline
\end{tabular}


Table 4

Multivariable Mixed-Model Linear Regression Analysis for Pain Scores at 1-Year $(\mathrm{N}=428)$

\begin{tabular}{lc}
\hline & $\underline{\mathbf{B}(\mathbf{9 5 \%} \mathbf{C I})}$ \\
Current Smoker vs. Never/Former & $.46(.17, .75)^{*}$ \\
Surgeon < 5 years of Experience & $.35(.05, .65)^{*}$ \\
Proximal vs. Middle/Distal & $.30(-.19, .78)$ \\
Open vs. Closed Fracture & $-.08(-.39, .24)$ \\
Superior vs. Inferior Portal & $.17(-.15, .49)$ \\
Tendon Split vs. Medical Paratendinous & $.03(-.32, .38)$ \\
\hline
\end{tabular}

Ref $=$ reference CI $=$ confidence interval

P $<.05$

(


Table 5

Multivariable Mixed-Model Logistic Regression Analysis for Activity

\begin{tabular}{|c|c|c|c|c|}
\hline & Kneel (N=387) & Run $(\mathrm{N}=\mathbf{3 8 5})$ & Stairs $(\mathbf{N}=\mathbf{3 9 0})$ & Walk Prolonged $(\mathrm{N}=\mathbf{3 8 5})$ \\
\hline & OR $(95 \% \mathrm{CI})$ & OR $(95 \% \mathrm{CI})$ & OR $(95 \% \mathrm{CI})$ & OR $(95 \% \mathrm{CI})$ \\
\hline Age & $1.0(.99,1.01)$ & $1.01(1.0,1.01)^{*}$ & $1.01(1.0,1.01)^{*}$ & $1.01(1.0,1.01)^{*}$ \\
\hline Female vs. Male (ref) & $1.1(1.0,1.3)^{*}$ & - & - & - \\
\hline Current Smoker vs. Never/Former & - & - & $1.1(1.0,1.3)^{*}$ & $1.2(1.1,1.3)^{*}$ \\
\hline AO Class A vs. B/C & - & $.93(.85,1.0)$ & - & - \\
\hline Proximal vs. Middle/Distal & $1.0(.86,1.2)$ & $1.1(.92,1.3)$ & $1.2(1.0,1.4)^{*}$ & $1.1(.89,1.3)$ \\
\hline Open vs. Closed Fracture & $1.0(.92,1.1)$ & $1.1(.98,1.2)$ & $1.2(1.0,1.2)$ & $1.2(1.1,1.3)^{*}$ \\
\hline Superior vs. Inferior Portal & $1.0(.91,1.1)$ & $1.1(.96,1.2)$ & $1.1(1.0,1.3)^{*}$ & $1.1(.95,1.2)$ \\
\hline Tendon Split vs. Medical Paratendinous & $.95(.85,1.1)$ & $1.1(.94,1.2)$ & $1.0(.89,1.1)$ & $1.0(.88,1.1)$ \\
\hline
\end{tabular}

Ref $=$ reference $; \mathrm{CI}=$ confidence interval

* $\mathrm{P}<.05$ 